\title{
EFFECT OF CHEMO-MECHANICAL CARIES REMOVAL ON THE MICRO-TENSILE BOND STRENGTH OF RESIN COMPOSITE USING UNIVERSAL ADHESIVE TO CARIES AFFECTED DENTINE
}

\author{
Hend S. Ahmed * and Hossam A. Alhussiny **
}

\begin{abstract}
Aim: to evaluate effect of chemo-mechanical caries removal on micro-tensile bond strength ( $\mu \mathrm{TBS})$ of composite using universal adhesive to caries affected dentine.

Materials and methods: 64 permanent molars were used. 32 were sound and the other (32) were carious. Carious molars were divided into four groups as followed Group 1: caries was removed by Carisolv then universal adhesive was applied with etch and rinse approach followed nanohybrid composite to be tested with $\mu$ TBS test after 24h. Group 2: as group (1) but tested after 3 months. Group 3: same as group (1) but using self-etch mode and tested after 24h. Group 4: as group (3) but tested after 3 months. Sound molars were divided into four groups according to bonding mode and according to the time of bond strength testing. Carisolv was applied according to manufacturer's instructions. The universal adhesive used with both approaches following the manufacturer's recommendations. Nanohybrid composite was packed. For delayed groups specimens were stored in distilled water for 3 months. The specimens were cut to produce $1 \mathrm{~mm}^{2}$ beam-shaped specimens for $\mu$ TBS test. The fractured specimens were examined to determine mode of failure.
\end{abstract}

Results: there was a statistically significant difference in $\mu$ TBS values between different adhesive approaches at each storage time. Etch \& Rinse approach yielded significantly highest $\mu$ TBS mean values in both Caries affected dentin and sound dentin for both times.

Conclusion: the etch and rinse approach is the indicated approach for bonding of the used universal adhesive to caries affected dentin especially after chemo-mechanical caries removal.

KEYWORDS: chemo-mechanical caries removal, caries affected dentin, multimode universal adhesive and microtensile bond strength

Lecturer of Restorative Dentistry, Faculty of Dentistry, The British University in Egypt, Cairo, Egypt

** Associate Professor of Operative Dentistry, Faculty of Dentistry, Suez Canal University, Egypt 


\section{INTRODUCTION}

Management of dental caries have been changed in the past years to achieve the conservative approach. The advances in adhesive dentistry, tooth colored restorative materials and understanding of minimal invasive dentistry as well as the remineralization of tooth structure allows the moving from "extension for prevention" concept of GV Black to the concept of "prevention of extension." Minimal removal of hard tooth structure achieves the conservative approach and prevents the progress of cavitated carious lesion $^{1,2}$

Caries removal using the conventional methods as rotary instruments results in extensive loss of the tooth structure and removal of most of the caries-affected dentin ${ }^{2,3}$. Different mechanical caries removal procedures were developed including burs, atraumatic restorative treatment, air abrasion and laser ${ }^{4}$. Concerning the conservative approach, alternative methods for caries removal were needed to avoid painful removal and preserve sound tooth structure. The introduction of new products for chemo-mechanical caries removal helped in development of minimally invasive approaches ${ }^{4}$.

Chemo-mechanical caries removal method removes only the infected dentin, preserving the healthy tooth structure with minimization of patient discomfort as well as pulpal irritation ${ }^{2,5,6}$. In the late 1970, a non-invasive technique activity of a solution of monochloro-amino-butyric acid (MAB) has been introduced and its action involves disruption of collagen of carious dentin and aids its removal ${ }^{2,7}$.

Few years after, a new chemo-mechanical caries removal solution was developed in the 1980s, by adding sodium chloride, glycine, $5 \%$ sodium hydroxide and aminobutyric acid, named Caridex. The new solution has many limitations as the complexity of its delivery equipment and the long time needed for caries removal in comparison to the conventional methods ${ }^{2,8,9}$.
So development of new solution was crucial to make the chemo-mechanical caries removal concept possible and applicable. Carisolv solution was introduced with similar mode of action of Caridex except that the monoaminobutyric acid in Caridex is replaced by three naturally amino acids glutamic acid, leucin and lysin. These three amino acids have different charges and can effectively interact with carious dentin, denaturing the collagen, making the dentin more softer and easier to remove with hand instruments ${ }^{4}$.

Carisolv is a sodium-hypochlorite-based (Na$\mathrm{OCl})$ agent, which facilitates the removal of carious dentin by chlorinating and disrupting hydrogen bonds of the partially degraded collagen ${ }^{9,10}$. The newly developed Carisolv has no adverse effects on pulp, healthy dentin, or oral mucosa ${ }^{6,11}$. Moreover, it showed high efficiency and in caries removal in both in vitro and in vivo studies ${ }^{6,12}$.

Achieving an intimate adaptation between a bonded restorative material with the dental substrate is an ultimate goal. Although it is difficult to achieve because the bonding process is different to enamel than that to dentin. As dentin is more organic and wet than enamel. Wetness of dentin, pulpal pressure and thickness of dentin are very important factors that should be considered during bonding process. Bonding to caries affected dentin is hindered by its low hardness and by the presence of mineral deposits in the dentinal tubules ${ }^{13}$.

Caries affected dentin show marked change in mineral content, loss of crystallization, and changing of the organic matrix. Bonding to cariesaffected dentin is considered one of the most debatable topics in adhesive dentistry ${ }^{9,14}$. Some studies have reported higher bond strengths of etchand-rinse adhesives than self-etching adhesives to caries-affected dentin ${ }^{9,15,16}$. On the other hand, other studies have declared that acid etching might lead to loss of the inorganic content of the caries affected dentin ${ }^{17,18}$. Which results in reduced hybridization of 
the demineralized caries-affected dentin by adhesive $\operatorname{resin}^{9,19}$. Accordingly, selecting the appropriate adhesive system compatible with caries-affected dentin is considered a controversial topic ${ }^{9,20}$.

The bonding to dentine involves the infiltration of resin into the demineralized inter-tubular dentin and dentinal tubules and formation of a 'hybrid' layer and resin $\operatorname{tags}^{21,22,23}$. The most commonly used bonding approaches to dentine used in clinical work are 'etch-and-rinse' and 'self-etch' techniques. The etch-and-rinse bonding system requires application of an etchant to enamel and dentine, followed by the application of a bonding agent which consists of primer and adhesive ${ }^{23}$. This process is technique sensitive because the etching and bonding occurs at different steps, the possibility that resin may not be able to penetrate the full depth of demineralized dentine. Furthermore, the main disadvantage of etch-and-rinse adhesive systems is that the collagen fibers collapse due to the dryness of demineralised dentin; which results bond strength reduction ${ }^{21,24}$.

To overcome these difficulties, self-etch adhesives were introduced. Self- etch systems have declared to be reliable and less technique sensitive. Self-etch adhesive systems do not include a separate etching step because they involve an aqueous mixture of acidic functional monomers, usually phosphoric-acid esters ${ }^{25}$, and the degree of moisture affects them less than etch-and-rinse adhesives ${ }^{26}$. Several studies recommend phosphoric acid for etching of the enamel, especially in the selective-etch technique when cavity margins are in the enamel ${ }^{27}$.

Universal adhesives were introduced in clinics since 2011. They are also known as multi-mode or multi-purpose adhesives. As they can be used as Self-Etch adhesives and Etch and Rinse adhesives according to the treatment of the substrate before application of the adhesive ${ }^{28,29,30}$. Using the selective-etch approach, these systems enabling the implementation of the etch and rinse with enamel to improve weakness of the previous generation single-step SE adhesives to enamel. While with dentin, it works with self-etch approach that provide good bonding to dentin without any biological complications ${ }^{28,31}$.

Dentin bonding with resins is affected by the morphological variations in the dentinal surface ${ }^{13}$. The outer layer of carious dentine 'infected dentine' demand complete excavation because it is highly decalcified with irreversibly denatured collagen fibers. On the other hand, the inner layer of carious dentin 'affected dentine', is relatively less decalcified and does not require removal ${ }^{13,32}$.

Studies give contradictory results concerning the bond strength of etch and rinse and self-etching systems to caries affected dentine ${ }^{33,34}$. It had been stated that etch-and-rinse adhesives had greater bond strength than self-etch adhesives and normal dentine samples had higher bond strength than caries affected dentine ${ }^{35}$. Caries removal methods might affect the bond strength of resin adhesives to dentin ${ }^{36}$.

The aim of the present study was to evaluate the effect of chemo-mechanical caries removal on the micro-tensile bond strength of universal adhesive implemented with an etch-and-rinse approach and self-etch approach to caries affected dentine. The null hypothesis was that neither the chemomechanical caries removal method nor different approaches of the universal adhesive have any effect on bond strength to caries affected dentine.

\section{MATERIALS AND METHODS}

\section{Sample size calculation}

Sample size calculation was conducted using G*Power 3.1.9.4 Software based on data obtained from previous studies (Mohammadi et al, 2015). The power of t-test was set at $90 \%$ using a twotailed significance level of 5\%. A sample size of 6 bonded assemblies per group was estimated. Sample 
TABLE (1): Name and product details of the materials used in this study

\begin{tabular}{|c|c|c|c|c|}
\hline Material & Specifications & Composition & Manufacturer & Lot number \\
\hline Carisolv & $\begin{array}{l}\text { Chemo- } \\
\text { mechanical } \\
\text { caries removal } \\
\text { gel }\end{array}$ & $\begin{array}{l}\text { Gei 1:0.1 M aminoacids (glutamic acid, ieuchin, lysin) sodium } \\
\text { chlo- rite, sodium hydroxide, erythro- sine, purified water } \\
\text { Gei 2; } 05 \% \text { sodium hypochlorite }\end{array}$ & $\begin{array}{l}\text { Mediteam } \\
\text { Dental AB, } \\
\text { Sweden }\end{array}$ & $812 G 2839$ \\
\hline $\begin{array}{c}\text { Prime \& } \\
\text { Bond active }\end{array}$ & $\begin{array}{l}\text { Universal } \\
\text { adhesive }\end{array}$ & $\begin{array}{l}\text { Phosphoric acid modified acrylate resin; Multifunctional } \\
\text { acrylate; Bifunctional acrylate; Acidic acrylate; Isopropanol; } \\
\text { Water; Initiator; Stabilizer. Mono-, di- and trimethacrylate } \\
\text { resins; PENTA Diketone; Organic phosphine oxide; Stabilizers; } \\
\text { Cetylamine hydrofluoride; Acetone; Water, MDP monomer }\end{array}$ & $\begin{array}{l}\text { DENTSPLY } \\
\text { sirona, } \\
\text { Konstanz, } \\
\text { Germany }\end{array}$ & 1908001270 \\
\hline $\begin{array}{l}\text { Ceram x- } \\
\text { SpherTEC }\end{array}$ & $\begin{array}{l}\text { Nanohybrid } \\
\text { composite } \\
\text { material }\end{array}$ & $\begin{array}{l}\text { Matrix: } \\
\text { (methacrylate-, acid-modified methacrylate-, inorganic } \\
\text { polycondensate- or epoxide based) modified version of the } \\
\text { polysiloxane. it is combined with a well-established poly- } \\
\text { urethane-methacrylate as well as bis-EMA and TEGDMA. } \\
\text { Fillers: } \\
77-79 \text { weight-\% total (59-61\% by volume) }\end{array}$ & $\begin{array}{l}\text { DENTSPLY } \\
\text { sirona, } \\
\text { Konstanz, } \\
\text { Germany }\end{array}$ & 1907000787 \\
\hline
\end{tabular}

size was increased by $30 \%$ to 8 bonded assemblies per group, for a total of 64 bonded assemblies per 8 groups, in order to compensate for pre-test failures.

\section{Specimens preparation}

Sixty-four freshly extracted permanent molars were obtained due to periodontal problems. They were stored in deionized water with $0.1 \%$ thymol to avoid bacterial growth. Half of the samples (32) were sound and the other half (32) was with carious lesions. The size of carious lesions were with moderate extension into dentin (cavitation) but not into the pulp chamber of the tooth, this was assessed during procedure of caries removal and teeth with caries extending more than half-way into dentin or extending into the pulp were excluded. Regarding the carious molars, roots were removed perpendicular to the long axis of the tooth with diamond disc parallel to the occlusal surface leaving $4 \mathrm{~mm}$ of the root to facilitate the specimens fixation. The specimens were washed thoroughly and dried with a triple syringe, and caries was identified visually and under 4x magnifying loupe (Univet, Italy).

\section{Specimens grouping}

The carious molars were divided into four groups (8 specimens for each) and assigned as followed.

Group 1: the carious dentin was removed by clear Carisolv gel (Mediteam Dental AB, Sweden) according to manufacturer's instructions till hard dentin was obtained then the universal adhesive was applied with etch and rinse approach followed by packing of nanohybrid resin composite to be tested with micro-tensile bond strength test after $24 \mathrm{~h}$ (immediate).

Group 2: the carious dentin was removed as group 1 then the universal adhesive was applied with etch and rinse approach followed by packing of nanohybrid resin composite to be tested with microtensile bond strength test after 3 months (delayed).

Group 3: the carious dentin was removed by clear Carisolv gel (Mediteam Dental AB, Sweden) according to manufacturer's instructions till hard dentin was obtained then the universal adhesive was applied with self-etch approach followed by packing of nanohybrid resin composite to be tested 
with micro-tensile bond strength test after $24 \mathrm{~h}$ (immediate).

Group 4: the carious dentin was removed as group 3 then the universal adhesive was applied with self-etch approach followed by packing of nanohybrid resin composite to be tested with microtensile bond strength test after 3 months (delayed).

The sound molars were divided into four groups (5 to 8 ) according to the bonding approach used with the universal adhesive either etch and rinse or self-etch and according to the time of bond strength testing either immediately (after 24 hours) or after 3 months.

\section{Specimens fixation}

Using cylindercal Teflon mold with separating medium applied on its internal walls; the $4 \mathrm{~mm}$ remaining of roots of each molar were placed in self-cure acrylic resin (Acrostone, Egypt) placed in the cylindrical mold. Each molar was embedded in the acrylic while it was in soft dough stage and pressed in the acrylic till the $4 \mathrm{~mm}$ of the remaining root is embedded to cemento-enamel junction with the long axis of the molar perpendicular to the base of the block. After acrylic setting the block was removed from the mold and checked carefully.

\section{Chemo-mechanical agent application and dentin caries removal}

For the carious molars, the Carisolv gel was mixed using twin multi mix syringe dispenser and applied to the carious lesions using a cotton pellet for 30 seconds and the carious dentin was excavated using number two hand instrument. After application, the gel was contaminated with debris and removed with a cotton pellet. Another fresh gel was applied to repeat the procedure until the gel became clear and the dentin surface felt hard using blunt dental explorer. Using wet cotton pellet, the remaining gel was washed. The cavity was checked with $4 \mathrm{x}$ magnifying loupe (Univet, Italy) and the remaining cusps were ground to provide nearly flat surface to facilitate composite packing and focus the bonding on the floor without effect of the bonded walls. While for the sound molars, the occlusal surface was ground to expose the mid dentin on which the composite was bonded and packed.

\section{Adhesive application}

The universal adhesive Prime and Bond Universal (DENTSPLYSirona, Konstanz, Germany) was used with etch and rinse and self-etch approaches according to the assigned group following the manufacturer's recommendations. For the etch and rinse approach, the dentin was etched for 10 second using phosphoric acid etchant gel (DeTrey conditioner 36, DENTSPLYSirona, Konstanz, Germany) then rinsed with air-water spray for 10 seconds using the triple syringe followed by drying by gentle air for 5 seconds. The adhesive was applied with the microbrush (Microbrush, USA) and left for 20 seconds and then air thinned for 10 seconds and cured for 20 seconds using LED lightcuring unit (Elipar S10, 3M ESPE, St Paul, MN, USA) operating in standard mode at light intensity $1200 \mathrm{~mW} / \mathrm{cm}^{2}$. Light intensity output was checked every 10 specimens with a radiometer from the same manufacturer. For the self-etch approach, the dentin was not etched with phosphoric acid, the universal adhesive was actively applied with the microbrush (Microbrush, USA) with rubbing movement for 20 seconds and then air thinned for 10 seconds followed by curing for 20 seconds using the same light curing unit.

\section{Packing of resin composite:}

Nanohybrid composite Ceram-x-SpherTEC (DENTSPLYSirona, Konstanz, Germany) was used in this study. The composite was packed on the bonded dentin surface incrementally. The first increment of $2 \mathrm{~mm}$ thickness was packed and cured for 20 seconds using the same light curing unit followed by $1 \mathrm{~mm}$ increment that was cured with the 
same protocol. Finally, $3 \mathrm{~mm}$ thick composite block was obtained on each specimen.

\section{Storage of the specimens}

For the immediate groups (group 1,3,5 and 7) specimens were stored in distilled water at room temperature for only $24 \mathrm{~h}$ before micro-tensile bond testing. On the other hand, regarding the delayed groups (group 2, 4, 6 and 8) specimens were stored in distilled water at room temperature for 3 months and the water was changed every 3 days.

\section{Micro-tensile bond strength testing}

The specimens were sectioned along the buccolingual and mesiodistal planes using a diamond disk (MTI Corporation, Richmond, CA, USA) in a low speed micro-slicing machine (Isomet, Buehler, Lake Bluff, IL, USA) under water-cooling, to produce beam-shaped specimens (bonding areas approximately $1 \mathrm{~mm}^{2}$ ). Centralized 3 to 4 beams were taken from each specimen. The bond strength test was performed immediately after cutting. The beam specimens were attached with cyanoacrylate gel (Zapit; Dental Ventures of America, Corona, CA, USA) to the testing customized microtensile jig. This jig is designed to transmit tensile forces to the specimen purely without any torque and designed to fit the $\mu$ TBS Instron Universal testing machine (Bisco Inc. Schaumburg, IL, USA). The tensile load was applied at a cross-head speed of $0.5 /$ minute until specimen failure occurred. At this point the failure load in Newton was recorded. The bond strength was calculated as the ratio between the failure load and the beam area that was checked with a digital caliper before testing.

\section{Failure mode analysis}

The fractured specimens were examined using a digital microscopic (Scope Capture Digital Microscope, Guangdong, China) at 50X magnification and photographed using image analysis software (Scope Capture 1.1.1.1. Ltd Co.) to determine the mode of failure either (1) adhesive failure along the composite-dentin interface, (2) cohesive failure within resin composite, (3) cohesive failure within the adhesive, (4) mixed failure.

\section{Statistical analysis}

Statistical analysis was performed using IBM SPSS Statistics Version 20. Data was presented as mean and standard deviation (SD). Significance level was set at $\mathrm{P}=0.05$. Kolmogorov-Smirnov and Shapiro-Wilk tests were used to assess data normality. One-Way ANOVA and Tukey's HSD post-hoc test were conducted to compare $\mu$ TBS values between different adhesive approaches. Independent Student-test was performed to compare $\mu$ TBS values between both storage times.

\section{RESULTS}

One-Way ANOVA followed by Tukey's HSD post-hoc test (Table 2) showed that there was a statistically significant difference in $\mu$ TBS values between different adhesive approaches at each storage time $(\mathrm{P}<0.001$ at 24 hours and $\mathrm{P}=0.003$ at 3 months). At 24 hours, Etch \& Rinse (E\&R) approach yielded significantly higher $\mu$ TBS mean values in both Caries affected dentin and sound dentin; while self-etch (SE) approach showed significantly lower $\mu$ TBS values in both Caries affected dentin and sound dentin. At 3 months, E\&R approach yielded the significantly highest $\mu$ TBS mean values when in Caries affected dentin; while $\mu$ TBS mean values of E\&R approach in sound dentin did not differ significantly from those of E\&R approach in sound dentin and SE approach in both Caries affected dentin and sound dentin.

Independent Student-test (Table 2) showed that $\mu$ TBS mean values recorded after 24 hours were significantly higher than those recorded after 3 months $(\mathrm{P}<0.001$ Caries affected dentin $+\mathrm{E} \& \mathrm{R}$ approach, $\mathrm{P}=0.001$ Caries affected dentin $+\mathrm{SE}$ approach, $\mathrm{P}<0.001$ sound dentin+E\&R approach, and $\mathrm{P}=0.015$ sound dentin+SE approach). 
TABLE (2) Mean \pm SD for the effect of adhesive approach and storage time on $\mu$ TBS values.

\begin{tabular}{|l|c|c|c|}
\hline & $\mathbf{2 4}$ hours & $\mathbf{3}$ months & P-value \\
\hline Caries affected dentin + E\&R approach & $27.57 \pm 0.95^{\mathrm{a}}$ & $23.28 \pm 1.28^{\mathrm{a}}$ & $<0.001^{*}$ \\
\hline Caries affected dentin + SE approach & $23.02 \pm 0.82^{\mathrm{b}}$ & $20.95 \pm 0.99^{\mathrm{b}}$ & $0.001^{*}$ \\
\hline Sound dentin + E\&R approach & $27.03 \pm 1.09^{\mathrm{a}}$ & $21.99 \pm 1.65^{\mathrm{ab}}$ & $<0.001^{*}$ \\
\hline Sound dentin + SE approach & $22.72 \pm 1.42^{\mathrm{b}}$ & $20.71 \pm 1.18^{\mathrm{b}}$ & $0.015^{*}$ \\
\hline P-value & $<0.001^{*}$ & $0.003^{*}$ & \\
\hline
\end{tabular}

*: significant at $P \leq 0.05 ;$ NS: non-significant at $P>0.05$

TABLE (3) Distribution of failure modes of resin composite bonded to caries affected dentin after Carisolv application

\begin{tabular}{|c|c|c|c|c|}
\hline Mode of failure & $\begin{array}{c}\text { Group 1 } \\
\mathbf{N = 2 4}\end{array}$ & $\begin{array}{c}\text { Group 2 } \\
\mathbf{N = 2 4}\end{array}$ & $\begin{array}{c}\text { Group 3 } \\
\mathbf{N = 2 4}\end{array}$ & $\begin{array}{c}\text { Group 4 } \\
\text { N=24 }\end{array}$ \\
\hline Adhesive at composite-dentin interface (\%) & $4(16.7)$ & $10(41.7)$ & $8(33.3)$ & $13(54.2)$ \\
\hline Cohesive failure within resin composite (\%) & $5(20.8)$ & $3(12.5)$ & $2(8.3)$ & $3(12.5)$ \\
\hline Cohesive failure within the adhesive (\%) & $9(37.5)$ & $7(29.1)$ & $9(37.5)$ & $6(25)$ \\
\hline Mixed failure (\%) & $6(25)$ & $4(16.7)$ & $5(20.8)$ & $2(8.3)$ \\
\hline
\end{tabular}

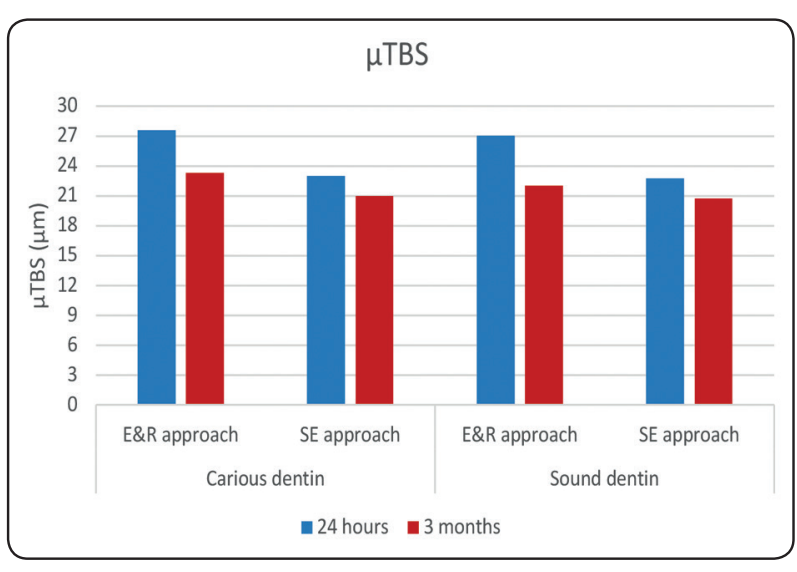

Fig. (1): Histogram showing the mean $\mu$ TBS of resin composite with different adhesive approaches at different times

\section{DISCUSSION}

Preservation of sound tooth structures during removal of carious lesions is one of the main objectives to adopt the conservative treatments. As removal of dentin caries using the conventional methods as the rotary instruments may sacrifice many sound dentin leaving the remaining tooth structure fragile and highly susceptible to fracture ${ }^{37,38,39}$. Therefore, many products were introduced for more conservative caries removal by chemical action rather than the mechanical ones, these products can selectively remove affected dentin and preserve demineralized-remineralizable dentin ${ }^{40}$.

Carisolv is one of these products utilizing $\mathrm{NaOCl}$ that ruptures the cross links between the dentinal collagen fibrils, denaturing them and dissolving the necrotic tissue. The bond between $\mathrm{NaOCl}$ and 
the amino acid reduces the effect of whole collagen denaturing and rupturing only the link between the affected collagen fibrils, without any molecular alterations occurring. ${ }^{41}$ Carisolv removes only the infected and necrotic dentin that no longer capable of being remineralized. Concerning the bottom uninfected dentin, it will be preserved. Moreover, the smear layer will be removed facilitating infiltration of adhesives ${ }^{42}$ enhancing the bonding of restorative materials. ${ }^{43}$

Bonding to tooth structures is one of the most important factors affecting the success of restorative dentistry. The bonding mechanism of adhesive systems used today to dentin is defined as a natural micromechanical bonding with the penetration of adhesive resin in-between the collagen fibrils of dentin that exposed by acid etching. Formation of "Hybrid Layer" ${ }^{44}$ in other words' interdiffusion layer' is one of the basic mechanisms of dentin bonding. ${ }^{45}$

Over the years, adhesive systems have been classified many times according to the steps of clinical practice and modern adhesive strategies and sometimes through generations. The current classification that based on to the type of application in the clinic; etch and rinse (either 3 or 2 steps), Self-etch (either 2 or one step) and Universal (Multi-mode). ${ }^{46,47}$ Universal adhesives were introduced in 2011. They are also named as multi-mode or multi-purpose adhesives. These adhesive can be used as etch and rinse adhesives (ER) and/or self etch adhesives (SE) with a technique known as selective etch technique 48,49,50. These adhesives implement the etch and rinse approach with enamel and self-etch approach with dentin. They improved the weak bond of the previous generation (one-step SE adhesives) to enamel. They revealed good bond strengths to both enamel and dentin ${ }^{48,51}$. Most of universal adhesives are designed based on the same concept of all-in-one (one-step) SE adhesives. The $\mathrm{pH}$ of current universal adhesives varies between 2.2 and $3.2^{52,53}$. This $\mathrm{pH}$ range may be very effective for bonding with dentin, but they may not be effective with enamel, especially to prepared enamel ${ }^{54,55}$.
Universal adhesives contain carboxylate or phosphate monomer that binds to calcium in hydroxyapatite. Monomers such as methacryloyloxydecyl dihydrogen phosphate (10-MDP), silane, polyacrylic acid are often added to their structures. 10-MDP monomer provides chemical bonding to hydroxyapatite, which exists in both enamel and dentin tissue $^{56}$. Additionally, they also contain BPDM, PENTA (49) and polyalkenoic acid copolymers which can increase attachment to dental tissues ${ }^{57}$. The matrix of universal adhesives are formed of a combination of hydrophilic HEMA, hydrophobic UDMA and Bis-GMA monomers creating a bridge between hydrophilic dental structures and hydrophobic resin composite. The universal adhesives can be used with both direct and indirect restorations, and they are also compatible with self-cure, light-cure and dual-cure resin- cements ${ }^{58}$.

However, the main disadvantage of universal adhesives is their water content resulting in hydrolytic destruction. Therefore, it is recommended to apply hydrophobic resin on the polymerized universal adhesive ${ }^{48}$.

In this study the null hypothesis was rejected as the chemo-mechanical caries removal method and the different approaches of the universal adhesive had a significant effect on bond strength to caries affected dentine.

The results showed that there was a statistically significant difference in $\mu$ TBS values between different adhesive approaches of the same universal adhesive at each storage time $(\mathrm{P}<0.001$ at 24 hours and $\mathrm{P}=0.003$ at 3 months). At 24 hours, $\mathrm{E} \& \mathrm{R}$ approach yielded significantly higher $\mu$ TBS mean values in both Caries affected dentin and sound dentin; while SE approach showed significantly lower $\mu$ TBS values in both Caries affected dentin and sound dentin. This is might be due to the effect of dentin etching with phosphoric acid that removedthe smear layer and the remnants of carisolv gel as well as selectively deminaralize the inorganic part of dentin and expose more collagen fibrils with more infiltration of the applied adhesive and more micromechani- 
cal interlocking. Moreover, dentin surface energy was increased after carisolv application improving the wettability of the adhesive as Carisolv gel selectively removes carious dentin, leaving a surface with many overhangs and undercuts, with dentinal tubules both patent and occluded, and is claimed to disrupt the collagen fibers that have been alterated by the carious process. Bonding to this surface showed stronger bond than that with a conventional smear layer formed after dentin cutting with rotary tools. Additionally, caries affected dentin is partially demineralized with partial mineral loss. Consequently, the inter-tubular dentin had a higher degree of porosity than the sound inter-tubular dentin ${ }^{59}$. This porous nature of the inter-tubular dentin leads to formation of thicker hybrid layers in the cariesaffected dentin which allows for more diffusion of the adhesive ${ }^{59}$.

On the contrary, this was disagreed by some studies that have speculated that phosphoric acid etching after carisolv gel application dissolves the mineral of the tooth structure quickly and easily; hence, it is not recommended as an ideal method for promoting ionic bonding to the mineral component of the tooth structure ${ }^{60}$. In addition, Hosoya et al, found that the application of Carisolv before acid etching might alter the bond strength to dentin due to micromorphologic alterations in the form of irregular surfaces with the predominance of an amorphous layer in flakes covering the dentinal tubules. In some areas, a smear layer was observed, but with microfractures. All these alterations have an adverse effect on the bond strength even with etch and rinse approach ${ }^{61,62}$

The low bond strength with SE adhesive might be due to the high $\mathrm{pH}$ level of Carisolv that could neutralize acids in the adhesive in the form of acidbase reaction with decrease of the bond strength by reducing demineralization of the tooth affecting the infiltration of the adhesive ${ }^{63,64}$. Another possible reason could be incomplete removal of caries by Carisolv gel that might interfere with bonding efficiency ${ }^{63,64}$. Moreover, the remnants of carious dentin probably contains a significant amount of water that affect impregnation of the adhesive to these areas with significant decrease in bond strength ${ }^{65}$.

Many studies have shown that thicker hybrid layers were created in caries-affected dentin compared to normal dentin ${ }^{66,}{ }^{67}$.Probably, the increase in thickness of the demineralized layer does not allow the adhesive resin to fully infiltrate to the base of the demineralized dentin ${ }^{68,69}$. This is termed "poor quality" hybrid layers in cariesaffected dentin compared with normal dentin and exhibited significantly lower bond strengths. This was thought to be due to the increase in the thickness of the hybrid layer and organic substances in cariesaffected dentin that may interfere with uniform resin permeation or with complete resin polymerization ${ }^{70}$. The low acidity of the adhesive minimized the demineralization of dentin and may have resulted in denatured dentin fragments remaining within cariesaffected dentin after using the Carisolv system.

After storage for 3 months, E\&R approach yielded the significantly highest $\mu \mathrm{TBS}$ mean values when in Caries affected dentin; while $\mu$ TBS mean values of $E \& R$ approach in sound dentin did not differ significantly from those of $E \& R$ approach in sound dentin and SE approach in both Caries affected dentin and sound dentin. The $\mu$ TBS mean values recorded after 24 hours were significantly higher than those recorded after 3 months. This could be attributed to the effect of storage on the bonding durability. As most of the universal adhesives are hydrophilic; storing the specimens in water may have accelerated the degradation of the adhesive or collagen fibrils. This was in agreement with many studies that reviewed a significant decrease in bond strength to dentin After three months of storage $71,72,73$. The presence of water also may have caused swelling and a reduction in the frictional forces between the polymer chains as well as hydrolysis of the filler-matrix interfaces, leading to a decrease in the mechanical properties of the resin ${ }^{74,75}$. Moreover, the sodium hypochlorite in Carisolv gel ( $\mathrm{pH} 11)$ may cause some change to the dentin, especially the collagen. This was evidenced by the dentin beneath 
the hybrid layer being of small cracks and porosities that affect the durability of bonding ${ }^{76}$.

Concerning the failure modes of resin composite bonded to caries affected dentin after Carisolv application, after 24 hours the cohesive failure was the predominating failure mode with the etch and rinse approach followed by the mixed failure mode with the least adhesive mode. This might be attributed to the high bond strength to caries affected dentin due to the etching step that totally removed the smear layer and remnants of carisolv with maximum infiltration of the adhesive. While for the self-etch adhesive the adhesive mode was the most frequent mode followed by the cohesive mode within the adhesive. This might be due to reduced bond strength of this approach to dentin. As mentioned before neutralization of acidic monomer of the adhesive by high $\mathrm{pH}$ of carisolv remnants affected the simultaneous demineralization and infiltration of the adhesive.

After 3 month storage the adhesive mode was the most dominating mode of both approaches that might be due to the effect of storage with its adverse effect on the bond strength. It can be suggested that the growth of the initial defects at the adhesive/ dentin interface resulted in the increase of this failure mode pattern in the long term. In addition, smear plugs could be observed in some MTBSfractured surfaces. The limited penetration of monomers into the dentin may have weakened the bond performance of self-etch adhesive.

\section{CONCLUSION}

Under the conditions of this study, it was concluded that etch and rinse approach is the indicated approach for bonding of the used multimode universal adhesive to caries affected dentin especially after caries removal with chemo-mechanical method as Carisolv. In addition, reduction of the bond strength to dentin occurred after three months storage for both etch-and-rinse and self-etch modes of the universal adhesive.

\section{REFERENCES}

1. Fatma AH, Shehaby EI. Morphological and structural changes of dentin after caries removal by different caries removal techniques and their effect on the shear bond strength to poly acid modified resin composites. Cairo Dent J 2008;24:99-110.

2. Mohammadi N, Ferooz M, Eskandarian T, Bagheri R. Effect of Caries Removal Methods on the Shear Bond Strength of Resin and Glass Ionomer Adhesives to Primary Dentin. J Dent Biomater 2015;2(4):141-148

3. Fusayama T. Clinical guide for removing caries using 21caries-detecting solution. Quintessence lnt 1988;19: 397-401.

4. Erhardt M, Amaral C, Castro A, Ambrosano G, Pimenta L. In Vitro influence of Carisolv on Shear bond strength of Dentin Bonding Agents. J Rest Dent 2004;35:801-807

5. Chang P,Yan LJ, Li R. Evaluation of chemomechanical and traditional mechanical caries removal in indirect pulp capping of symmetric primary molars. Nan Fang Yi Ke Da Xue Xue Bao 2011;31:1568-1570.

6. Zawaideh F, Palamara JE, Messer LB. Bonding of Resin Composite to Caries-affected Dentin after Carisolv Treatment. Pediatr Dent 2011;33:213-220

7. Kronman JH, Goldman M, Habib CM. Electron Microscopic Study of Altered Collagen Structure after Treatment with N-monochloro-DL-2-aminobutyrate (GK-101 E). J Dent Res 1979;58:1914.

8. Burke FM, Lynch E. Chemomechanical caries removal. J Ir Dent Assoc 1995;41:10-14.

9. Hamama H, Yiu C, Burrow M. Effect of chemomechanical caries removal on bonding of self-etching adhesives to caries affected dentin. J Adhes Dent 2014;16:507-516

10. Maragakis GM, Hahn P, Hellwig E. Chemomechanical caries removal: a comprehensive review of the literature. Int Dent J 2001;51:291-299.

11. Arvidsson A, Stirling C, Sennerby L, Wennerberg A. Reactions in the oral mucous membrane after exposure to Carisolv Combined results from a clinical screening test in humans and an experimental study in rats. Gerodont 2001;18:109-113.

12. Peric T, Markovic D. In vitro effectiveness of a chemomechanical method for caries removal. Eur J Paediatr Dent 2007;8:61-67. 
13. Perdigao J. Dentin bond variables related to the clinical situation and the substrate treatment. J Dent Mater 2010;26(2):24-37

14. Zanchi CH, Lund RG, Perrone LR, Ribeiro GA, del Pino FA, Pinto MB, Demarco FF. Microtensile bond strength of two-step etch-and-rinse adhesive systems on sound and artificial caries-affected dentin. Am J Dent 2010;23:152-156.

15. Ceballos L, Camejo DG, Fuentes VM, Osorio R, Toledano M, Carvalho RM, Pashley DH. Microtensile bond strength of total-etch and self- etching adhesives to caries-affected dentine. J Dent 2003;31:469-477.

16. Scholtanus JD, Purwanta K, Dogan N, Kleverlaan CJ, Feilzer AJ. Micro- tensile bond strength of three simplified adhesive systems to caries- affected dentin. J Adhes Dent 2010;12:273-278.

17. Nakajima M, Sano H, Burrow MF, Tagami J, Yoshiyama M, Ebisu S, Ciucchi B, Russell CM, Pashley DH. Tensile bond strength and SEM evaluation of caries-affected dentin using dentin adhesives. J Dent Res 1995;74:1679-1688.

18. Yoshiyama M, Tay FR, Doi J, Nishitani Y, Yamada T, Itou K, Carvalho RM, Nakajima M, Pashley DH. Bonding of self-etch and total-etch adhesives to carious dentin. J Dent Res 2002;81:556-560.

19. Bussadori SK, Castro LC, Galvao AC. Papain gel: a new chemo-mechanical caries removal agent. J Clin Pediatr Dent 2005;30:115-119.

20. Omar H, El-Badrawy W, El-Mowafy O, Atta O, Saleem B. Microtensile bond strength of resin composite bonded to caries-affected dentin with three adhesives. Oper Dent 2007;32:24-30.

21. Aggarwal V, Singla M, Yadav S, Yadav H. The effect of caries excavation methods on the bond strength of etchand-rinse and self-etch adhesives to caries affected dentine. Aust Dent J 2013;58:454-460

22. Breschi L, Mazzoni A, Ruggeri A, Cadenaro M, Di Lenarda R, Dorigo ES. Dental adhesion review: aging and stability of the bonded interface. Dent Mater 2008;24:90-101.

23. Van Meerbeeck B, De Munck J, Yoshida Y. Buonocore memorial lecture. Adhesion to enamel and dentin: current status and future challenges. Oper Dent 2003;28:215-235.

24. Tay FR, Gwinnett JA, Wei SH. Micromorphological spectrum from overdrying to overwetting acid-conditioned dentin in water-free acetone-based, single-bottle primer/ adhesives. Dent Mater 1996;12:236-244.
25. Van Meerbeek B, Yoshihara K, Yoshida Y, Mine A, De Munck J, Van Landuyt KL. State of the art of self-etch adhesives. Dent Mater 2011;27:17-28.

26. Tay FR, King NM, Chan KM, Pashley DH. How can nanoleakage occur in self-etching adhesive systems that demineralize and infiltrate simultaneously? J Adhes Dent 2002;4:255-269.

27. Miller MB. Self-etching adhesives: solving the sensitivity conun- drum. Pract Proced Aesthet Dent 2002;14:406.

28. Hanabusa M, Mine A, Kuboki T, Momoi Y, Van Ende A, Van Meerbeek B. Bonding effectiveness of a new "multi-mode" adhesive to enamel and dentine. J Dent 2012;40:475-84

29. Perdigao J, Sezinando A, Monteiro PC. Laboratory bonding ability of a multi-purpose dentin adhesive. Am J Dent 2012;25:153-8.

30. Munoz MA, Luque-Martinez I, Malaquias P, Hass V, Reis A, Campanha $\mathrm{NH}$. In vitro longevity of bonding properties of universal adhesives to dentin. Oper Dent 2015;40:282-92.

31. Sezinando A. Looking for the ideal adhesive-A review. Rev Port Estomatol Cir Maxilofac 2014;55:194-206.

32. Ohgushi K, Fusayama T. Electron microscopic structure of the two layers of carious dentin. J Dent Res 1975;54: 1019-1026.

33. Wang Y, Spencer P, Walker MP. Chemical profile of adhesive/caries-affected dentin interfaces using Raman microspectrosco- py. J Biomed Mater Res A 2007;81:279-286.

34. Say EC, Nakajima M, Senawongse P, Soyman M, Ozer F, Ta-gami J. Bonding to sound vs. caries-affected dentin using photo- and dual-cure adhesives. Oper Dent 2005;30:90-98.

35. Ceballos L, Camejo DG, Victoria Fuentes M. Microtensile bond strength of total-etch and self-etching adhesives to caries- affected dentine. J Dent 2003;31:469-477.

36. Sonoda H, Banerjee A, Sherriff M, Tagami J, Watson TF. An in vitro investigation of microtensile bond strengths of two dentine adhesives to caries affected dentine. J Dent 2005;33:335-342.

37. McNierny HD, Petruzillo MA. A gentle approach to operative dentistry: The Caridex caries removal system. Gen Dent 1986;34:282-4.

38. Cavel WT, Kelsey WP 3rd, Barkmeier WW, Blankenau RJ. Clinical evaluation of chemomechanical removal of cervical caries. Gen Dent 1988;36:405-8. 
39. Gwinnett JA, Barkmeier WW. Morphology of dentin surfaces in chemomechanically prepared cavities. Am J Dent 1988;1:101-4.

40. Fusayama T. Two layers of carious dentin: Diagnosis and treatment. Oper Dent 1979;4:63-70.

41. Ericson D. Invitro efficacy of a new gel for chemomechanical caries removal. J Dent Res 1998;77:1252.

42. Naressi SCM, Araújo MAM. Comparison of marginal infiltration of adhesive restorations using a rotary instrument or a chemical-mechanical system to remove decayed tissue. RPG Rev Pós Grad 2001;8:313-21.

43. Emanuel R, Broome MJC. Surface energy of chemomechanically prepared dentin. Quintessence Int 1988; 19:369-72.

44. Nakabayashi N. Resin reinforced dentin due to infiltration of monomers into the dentin at the adhesive interface. JSDMD 1982;1:78-81.

45. Van Meerbeek B, Inokoshi S, Braem M, Lambrechts P, Vanherle G. Morphological aspects of the resin-dentin interdiffusion zone with different dentin adhesive systems. J Dent Res 1992;71:1530-40.

46. Van Meerbeek B, Perdigao J, Lambrechts P, Vanherle G. The clinical performance of adhesives. J Dent 1998;26:1-20.

47. Sofan E, Sofan A, Palaia G, Tenore G, Romeo U, Migliau G. Classification review of dental adhesive systems: From the IV generation to the universal type. Ann Stomatol 2017;8:1-17.

48. Hanabusa M, Mine A, Kuboki T, Momoi Y, Van Ende A, Van Meerbeek B. Bonding effectiveness of a new "multi-mode" adhesive to enamel and dentine. J Dent 2012;40:475-84.

49. Perdigao J, Sezinando A, Monteiro PC. Laboratory bonding ability of a multi-purpose dentin adhesive. Am J Dent 2012;25:153-8.

50. Munoz MA, Luque-Martinez I, Malaquias P, Hass V, Reis A, Campanha NH. In vitro longevity of bonding properties of universal adhesives to dentin. Oper Dent 2015;40: 282-92.

51. Sezinando A. Looking for the ideal adhesive-A review. Rev Port Estomatol Cir Maxilofac 2014;55:194-206.

52. Van Meerbeek B, Yoshihara K, Yoshida Y, Mine A, De Munck J, Van Landuyt KL. State of the art of selfetch adhesives. Dent Mater 2011;27:17-28.
53. Perdigao J, Lopes L, Lambrechts P, Leitão J, Van Meerbeek B, Vanherle G. Effects of a self-etching primer on enamel shear bond strengths and SEM morphology. Am J Dent 1997;10:141-6.

54. Tay FR, Pashley DH. Aggressiveness of contemporary self-etching systems. I: Depth of penetration beyond dentin smear layers. Dent Mater 2001;17:296-308.

55. Miyazaki M, Sato M, Onose H. Durability of enamel bond strength of simplified bonding systems. Oper Dent 2000;25:75-80.

56. Van Landuyt KL, Snauwaert J, De Munck J, Peumans M, Yoshida Y, Poitevin A. Systematic review of the chemical composition of contemporary dental adhesives. Biomaterials 2007;28:3757-85.

57. Hashimoto M, Ito S, Tay FR, Svizero NR, Sano H, Kaga $\mathrm{M}$. Fluid movement across the resin-dentin interface during and after bonding. J Dent Res 2004;83:843-48.

58. Van Meerbeek B, Perdigao J, Lambrechts P, Vanherle G. The clinical performance of adhesives. J Dent 1998; 26:1-20.

59. Dammaschke T, Stratmann U, Mokrys K. Reaction of sound and demineralized dentin to Carisolv in vivo and in vitro. J Dent 2002;30:59-65.

60. Tay FR, Smales RJ, Ngo H. Effect of different conditioning protocols on adhesion of a GIC to dentin. J Adhes Dent 2001;3:153-167.

61. Hosoya Y, Kawashita Y, Marshall Jr. GW, Goto G. Influence of Carisolv for resin adhesion to sound human primary dentin and young permanent dentin. J Dent 2001;29:163-71.

62. Correa FNP, Filho LER, Rodrigues CRMD. Evaluation of residual dentin after conventional and chemomechanical caries removal using SEM. J Clin Pediatr Dent 2007; 32(2):115-120

63. Cehreli ZC, Yazici AR, Akca T, Ozgunaltay G. A Morphological and microtensile bond strength evaluation of a single-bottle adhesive to caries affected human dentine after four different caries removal techniques. J Dent 2003;31(6):429-435.

64. Karaarslan ES, Yildiz E, Cebe MA, Yegin Z, Ozturk B. Evaluation of micro-tensile bond strength of caries affected human dentine after three different caries removal techniques. J Dent 2012;40(10):793-801 
65. Cederlund A, Lindskog S, Blomlöf J. Efficacy of Carisolv-assisted caries excavation. Inter J Perio \& Rest Dent 1999;19(5):464-469.

66. Nakajima M, Ogata M, Okuda M, Tagami J, Sano H, Pashley DH. Bonding to caries-affected dentin using self-etching primers. Amer J Dent 1999;12(6):309-314.

67. Nakajima M, Sano H, Urabe I, Tagami J, Pashley DH. Bond strengths of single-bottle dentin adhesives to cariesaffected dentin. Oper Dent 2000;25(1):2-10.

68. Eick JD, Gwinnett AJ, Pashley DH, Robinson SJ. Current concepts on adhesion to dentin. Critical Review in Oral Biology and Medicine 1977;8(3):306-335.

69. Prati C, Chersoni S, Mongiorgi R, Montanari G, Pashley DH. Resin-infiltrated dentin layer formation of new bonding systems. Oper Dent 1998;23(4):185-194.

70. Yoshiyama M, Urayama A, Kimochi T, Matsuo T, Pashley DH. Comparison of conventional vs self-etching adhesive bonds to caries-affected dentin. Oper Dent 2000;25(2): 163-169.

71. Feitosa VP, Leme AA, Sauro S, CorrerSobrinho L, Watson TF, Sinhoreti MA, Correr AB. Hydrolytic degradation of the resin-dentine interface induced by the simulated pulpal pressure, direct and indirect water ageing. J Dent 2012;40(12):1134-1143.

72. Reis AF, Giannini M, Pereira PN. Effects of a peripheral enamel bond on the long-term effectiveness of dentin bonding agents exposed to water in vitro. J Biomed Mater. Research Part B: Applied Biomaterials 2008;85(1):10-17.

73. Takahashi H. Effect of calcium salt of 10-methacryloyloxydecyl dihydrogen phosphate produced on the bond durability of one-step self-etch adhesive. Dent Mater J 2014;33(3):394-401.

74. Ferracane JL, Berge HX, Condon JR. In vitro aging of dental composites in water Effect of degree of conversion, filler volume, and filler/matrix coupling. J Biomed Mater Res 1998;42(3):465-472.

75. Takeshige F, Kawakami Y, Hayashi M, Ebisu S. Fatigue behavior of resin composites in aqueous environments. Dent Mater 2007;23(7):893-899.

76. Sakooloamarka R, Burrow MF, Kubo S, Tyas MJ. Morphological study of demineralized dentine after caries removal using two different methods. Aust Dent J 2002;47(2):116-122. 